\title{
Opportunistic validation of sulfur dioxide in the Sarychev Peak volcanic eruption cloud
}

\author{
S. A. Carn ${ }^{1}$ and T. M. Lopez ${ }^{2}$ \\ ${ }^{1}$ Department of Geological and Mining Engineering and Sciences, Michigan Technological University, \\ 1400 Townsend Drive, Houghton, MI 49931, USA \\ ${ }^{2}$ Geophysical Institute, University of Alaska Fairbanks, 903 Koyukuk Drive, Fairbanks, AK 99775, USA
}

Received: 6 June 2011 - Published in Atmos. Meas. Tech. Discuss.: 17 June 2011

Revised: 24 August 2011 - Accepted: 25 August 2011 - Published: 1 September 2011

\begin{abstract}
We report attempted validation of Ozone Monitoring Instrument (OMI) sulfur dioxide $\left(\mathrm{SO}_{2}\right)$ retrievals in the stratospheric volcanic cloud from Sarychev Peak (Kurile Islands) in June 2009, through opportunistic deployment of a ground-based ultraviolet (UV) spectrometer (FLYSPEC) as the volcanic cloud drifted over central Alaska. The volcanic cloud altitude $(\sim 12-14 \mathrm{~km})$ was constrained using coincident CALIPSO lidar observations. By invoking some assumptions about the spatial distribution of $\mathrm{SO}_{2}$, we derive averages of FLYSPEC vertical $\mathrm{SO}_{2}$ columns for comparison with OMI $\mathrm{SO}_{2}$ measurements. Despite limited data, we find minimum OMI-FLYSPEC differences within measurement uncertainties, which support the validity of the operational $\mathrm{OMI} \mathrm{SO}_{2}$ algorithm. However, our analysis also highlights the challenges involved in comparing datasets representing markedly different spatial and temporal scales. This effort represents the first attempt to validate $\mathrm{SO}_{2}$ in a stratospheric volcanic cloud using a mobile ground-based instrument, and demonstrates the need for a network of rapidly deployable instruments for validation of space-based volcanic $\mathrm{SO}_{2}$ measurements.
\end{abstract}

\section{Introduction}

Validation of satellite retrievals of trace gases is a crucial part of any mission, but the approach is highly dependent on the species in question. Some molecules (e.g., $\mathrm{NO}_{2}$ ) have well-characterized sources and somewhat predictable distri-

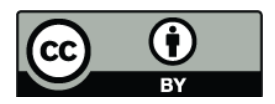

Correspondence to: S. A. Carn (scarn@mtu.edu) butions, making it easier to plan validation campaigns and extended deployments of ground-based or airborne instrumentation (e.g., Brinksma et al., 2008). However, this is not usually the case for volcanic $\mathrm{SO}_{2}$, emitted by largely unpredictable volcanic activity, often in remote locations. Validation of satellite $\mathrm{SO}_{2}$ measurements in such situations is mostly opportunistic (e.g., Carn et al., 2011), and may require rapid mobilization or deployment of ground-based assets (e.g., Spinei et al., 2010). Efforts to validate volcanic $\mathrm{SO}_{2}$ retrievals have become increasingly important in the light of recent volcanic ash crises (e.g., the 2010 Eyjafjallajökull eruption), during which satellite measurements of $\mathrm{SO}_{2}$ and ash were used to track the drifting volcanic clouds (e.g., Thomas and Prata, 2011).

We show here that useful $\mathrm{SO}_{2}$ validation data can be collected by rapid deployment of a simple, mobile ultraviolet (UV) spectrometer system similar to those used widely for volcano monitoring. The opportunity arose when the volcanic cloud produced by the June 2009 explosive eruption of Sarychev Peak (Matua Island, Kuril Is; $48.1^{\circ} \mathrm{N}, 153.2^{\circ} \mathrm{E}$ ) drifted over central Alaska. Satellite measurements of $\mathrm{SO}_{2}$ by the Ozone Monitoring Instrument (OMI) on NASA's Aura satellite were the object of validation. Our measurements represent the first attempt to validate $\mathrm{SO}_{2}$ in a drifting, stratospheric volcanic cloud using road-based vehicular traverses beneath the plume.

The 2009 eruption of Sarychev Peak began on 11 June. Haywood et al. (2010) provide an overview of the eruption and present $\mathrm{SO}_{2}$ data from the Infrared Atmospheric Sounding Interferometer (IASI) on the MetOp-A satellite, along with climate model simulations of volcanic cloud dispersion. IASI measured a total $\mathrm{SO}_{2}$ burden of $1.2 \pm 0.2 \mathrm{Tg}$ in the upper troposphere and lower stratosphere (UTLS) following the

Published by Copernicus Publications on behalf of the European Geosciences Union. 


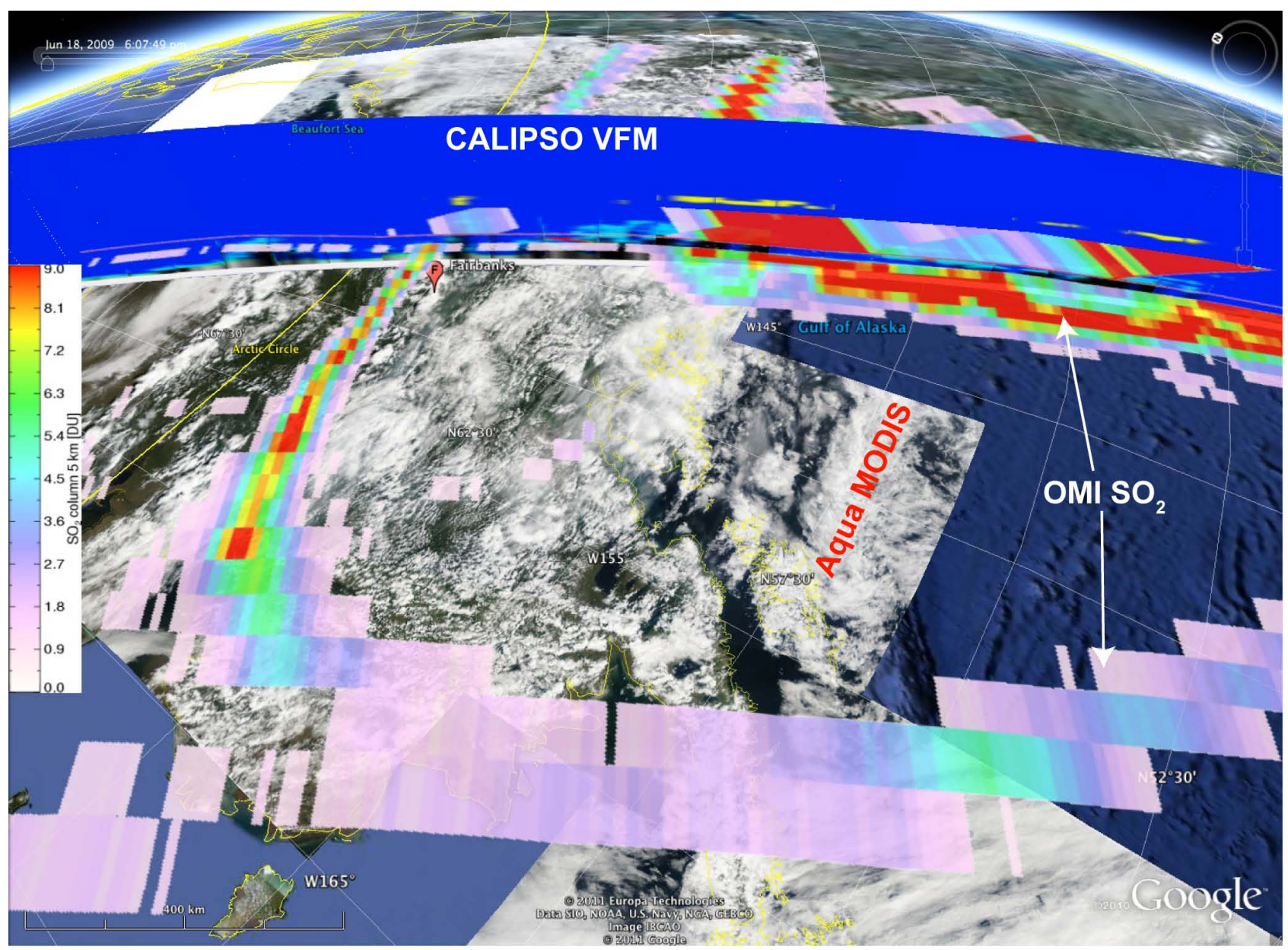

Fig. 1. Google Earth ${ }^{\mathrm{TM}}$ composite showing a perspective view of A-Train satellite observations of the Sarychev Peak volcanic cloud over Alaska on 18 June 2009. The datasets shown are true-color Aqua MODIS visible imagery ( 22:20 UTC; lowermost image), OMI $\mathrm{SO}_{2}$ columns ( 22:28 UTC; large colored pixels - color scale shown on left) and a CALIPSO lidar Vertical Feature Mask (VFM) curtain ( $\sim 22: 20$ UTC). Yellow features on the CALIPSO VFM curtain indicate stratospheric volcanic aerosol at altitudes of $\sim 12-15 \mathrm{~km}$. The location of Fairbanks, AK is indicated. The data (KMZ files) used to create this figure are available as a Supplement.

eruption sequence, which is commensurate with total $\mathrm{SO}_{2}$ burdens measured by OMI. Dispersion of the volcanic $\mathrm{SO}_{2}$ after eruption was complex but is not the focus of this paper. An animation of $\mathrm{OMI} \mathrm{SO}_{2}$ data showing dispersion of the Sarychev Peak $\mathrm{SO}_{2}$ cloud over the Northern Hemisphere from 10 June-31 July 2009 is available as Supplementary Online Material. Beginning on 15 June, the $\mathrm{SO}_{2}$ cloud began to drift across Alaska, providing the opportunity for validation described herein. In contrast to the $\mathrm{SO}_{2}$ clouds released by the eruptions of Okmok and Kasatochi (Aleutian Islands) in July-August 2008 (e.g., Spinei et al., 2010), the bulk of the Sarychev eruption cloud resided at high latitudes, presenting few opportunities for ground-based measurements.

\section{Data}

The Level 2 OMI dataset used here is derived from version 003 of the operational $\mathrm{SO}_{2}$ algorithm (hereafter referred to as OMSO2), the theoretical basis of which is described by Yang et al. (2007). We also use the Level 2 OMPIXCOR OMI Ground Pixel Corner Coordinate product. OMSO2 and OMPIXCOR data are publicly available from the NASA Goddard Earth Sciences (GES) Data and Information Services Center (DISC; http://daac.gsfc.nasa.gov/). Operational $\mathrm{OMI} \mathrm{SO}_{2}$ retrievals require an a-priori assumption of the vertical $\mathrm{SO}_{2}$ distribution (Yang et al., 2007), which is currently addressed by providing retrieved $\mathrm{SO}_{2}$ columns corresponding to four different a-priori $\mathrm{SO}_{2}$ profiles. For this analysis we use the mid-tropospheric (TRM) and lower stratospheric (STL) $\mathrm{SO}_{2}$ products, which correspond to $\mathrm{SO}_{2}$ layer center of mass altitudes (CMAs) of $\sim 7.5$ 
$532 \mathrm{~nm}$ Total Attenuated Backscatter $\left(\mathrm{km}^{-1} \mathrm{sr}^{-1}\right)$ UTC: 2009-06-18 22:12:29 to 2009-06-18 22:25:57

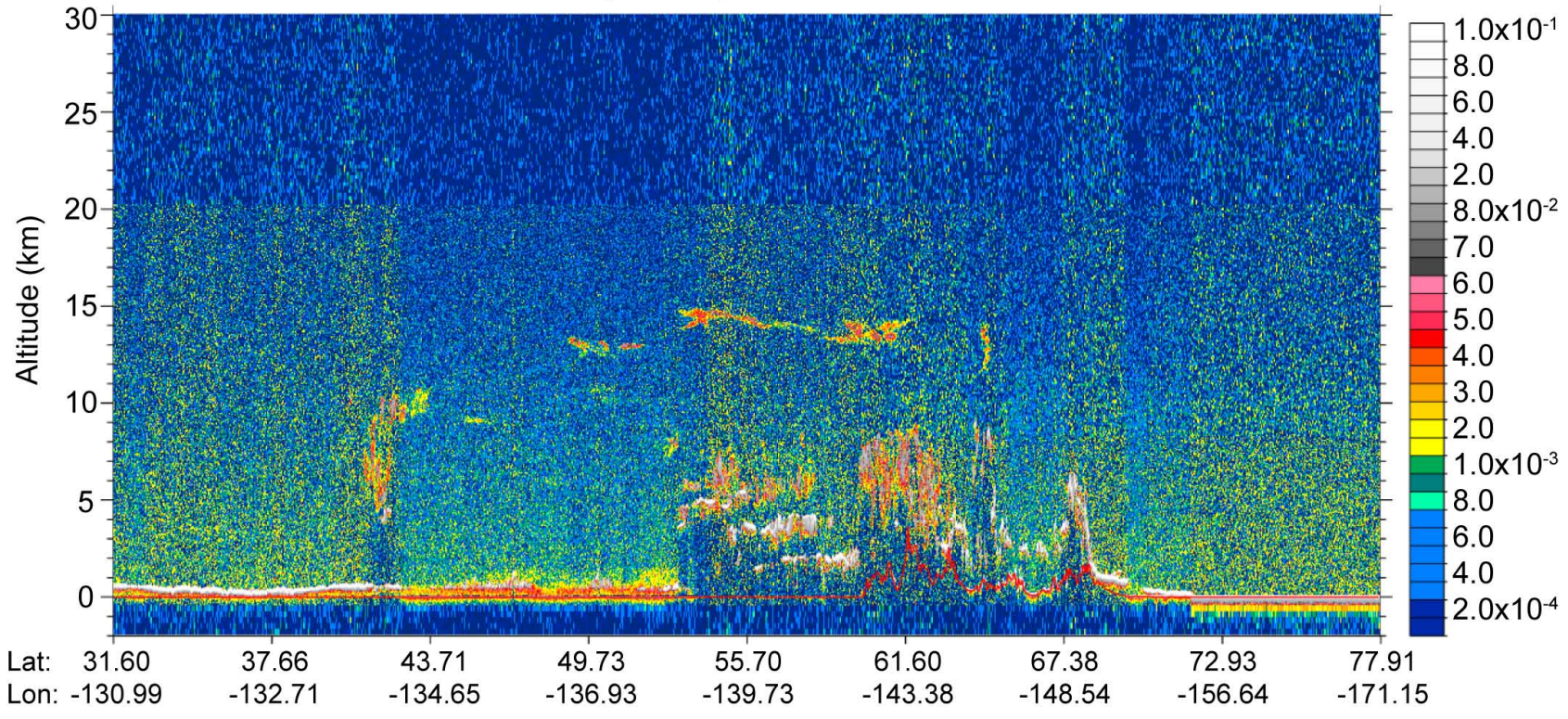

Fig. 2. $532 \mathrm{~nm}$ Total Attenuated Backscatter curtain from the Cloud-Aerosol Lidar with Orthogonal Polarization (CALIOP) aboard the CALIPSO satellite, collected at 22:12-22:26 UTC on 18 June 2009. This plot and other coincident CALIOP data can be seen at: http: //www-calipso.larc.nasa.gov/products/lidar/browse_images/show_date.php?s=production $\backslash \& v=V 3-01 \backslash \&$ browse_date=2009-06-18. Features showing elevated backscatter at altitudes above $\sim 11 \mathrm{~km}$ are probably all due to aerosol in the Sarychev Peak volcanic cloud, based on collocation with $\mathrm{SO}_{2}$ measured by OMI (Fig. 1). Low values of the lidar depolarization ratio in these features (not shown) suggest that the aerosol was dominated by liquid sulfate aerosol and/or liquid-coated solid particles. The volcanic cloud filament discussed in this paper is the northernmost volcanic aerosol feature at $\sim 64-65^{\circ} \mathrm{N}$.

and $\sim 17.5 \mathrm{~km}$, respectively. Overall uncertainty on the OMI $\mathrm{SO}_{2}$ retrievals (including CMA errors) for $\mathrm{SO}_{2}$ clouds above $5 \mathrm{~km}$ altitude is $\sim 20 \%$ (Yang et al., 2007). We also employ other NASA A-Train satellite datasets, including Moderate Resolution Imaging Spectroradiometer (MODIS) data from Aqua, and Cloud-Aerosol Lidar with Orthogonal Polarization (CALIOP) profiles from CALIPSO (Vaughan et al., 2004), to characterize meteorological clouds and assess volcanic cloud altitude (Figs. 1, 2).

Ground-based $\mathrm{SO}_{2}$ data were collected using a FLYSPEC, a simple but flexible and rapidly deployable UV spectrometer that is calibrated using integral $\mathrm{SO}_{2}$ gas cells (Horton et al., 2006). Conditions were favorable on 18 June 2009 as the Sarychev $\mathrm{SO}_{2}$ cloud drifted over southern and central Alaska (Fig. 1; see Supplement). The FLYSPEC was mounted on a vehicle and pointed to zenith, and a high-quality instrument calibration was obtained under clear-sky conditions in Fairbanks $\left(64.84^{\circ} \mathrm{N}, 147.72^{\circ} \mathrm{W}\right)$ at 21:06 UTC. Measurements of overhead $\mathrm{SO}_{2}$ column density were then performed south of Fairbanks along Route 3 towards Healy (Fig. 3), at a roughly constant speed of $\sim 100 \mathrm{~km} \mathrm{~h}^{-1}\left(\sim 27 \mathrm{~m} \mathrm{~s}^{-1}\right.$; Fig. 4). While this speed exceeds that typically recommended for road-based traverses of volcanic $\mathrm{SO}_{2}$ plumes $\left(10-60 \mathrm{~km} \mathrm{~h}^{-1}\right.$ ) (Williams-Jones et al., 2008), it was required by the large extent of the Sarychev $\mathrm{SO}_{2}$ cloud (Fig. 4). Further FLYSPEC calibrations were performed at 22:27, 22:42, 22:54 UTC on
18 June and 00:22 UTC on 19 June. Conversion of calibrated FLYSPEC data (in ppmm) to column densities in Dobson Units (DU; $1 \mathrm{DU}=0.02848 \mathrm{~g} \mathrm{~m}^{-2} \mathrm{SO}_{2}$ ) used the conversion derived by Gerlach (2003) $\left(1 \mathrm{ppmm}=2.663 \times 10^{-6} \mathrm{~kg} \mathrm{~m}^{-2}\right)$. Further mobile and stationary FLYSPEC measurements were also made in Fairbanks on 20 June, when the Sarychev $\mathrm{SO}_{2}$ cloud was again overhead. However, in this case the spatially extensive $\mathrm{SO}_{2}$ cloud precluded FLYSPEC calibration under clear-sky conditions, and these measurements are not discussed further here. Noise in FLYSPEC $\mathrm{SO}_{2}$ data has been reported to be $\sim 0.4-1.1 \mathrm{DU}$, with errors of up to $6 \%$ on retrieved $\mathrm{SO}_{2}$ columns based on testing with standard calibration cells (Elias et al., 2006).

\section{Results and discussion}

OMSO2 data show a filament of $\mathrm{SO}_{2}$ extending across central Alaska in the 22:28 UTC Aura overpass on 18 June 2009 (Fig. 1). CALIOP detected collocated aerosol (presumably sulfate) in the lower stratosphere at $\sim 12-14 \mathrm{~km}$ altitude in the 22:22 UTC CALIPSO overpass (Fig. 2), while Aqua MODIS data indicate partly cloudy conditions and visible haze south of Fairbanks (Fig. 3). Figure 3 shows southbound and northbound FLYSPEC traverses superimposed on the $\mathrm{OMI} \mathrm{SO}_{2}$ retrievals. FLYSPEC traverse profiles, showing 


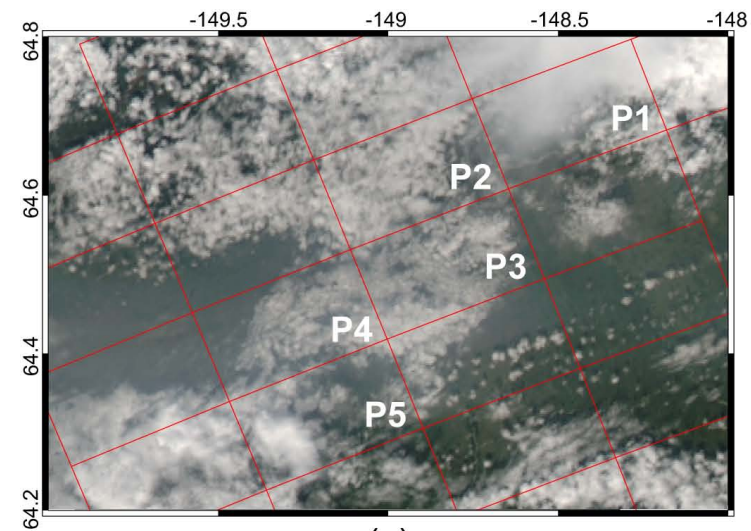

(a)

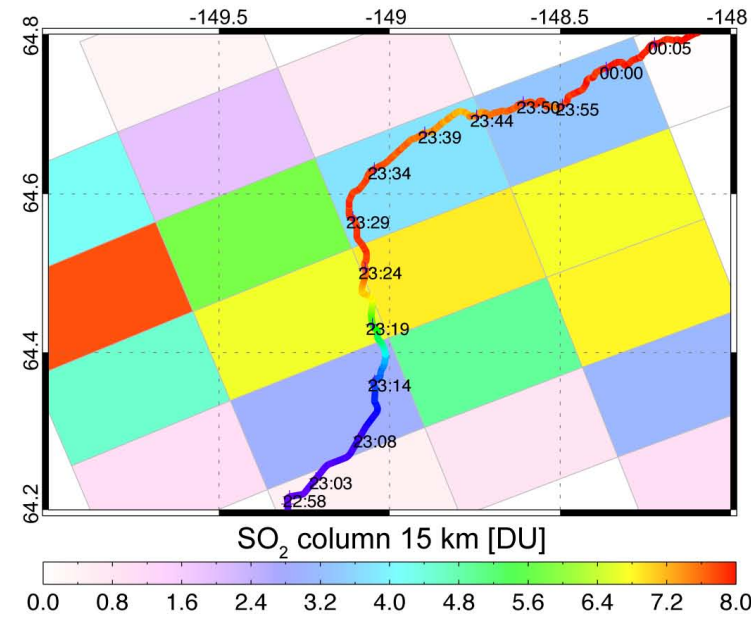

(c)

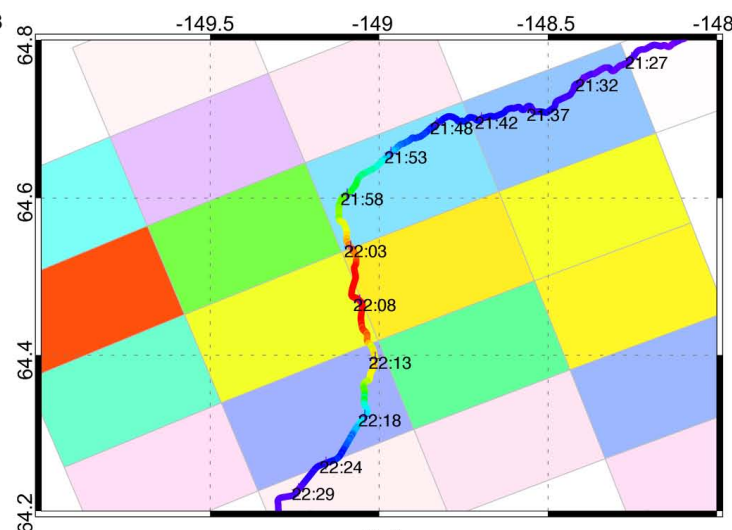

(b)

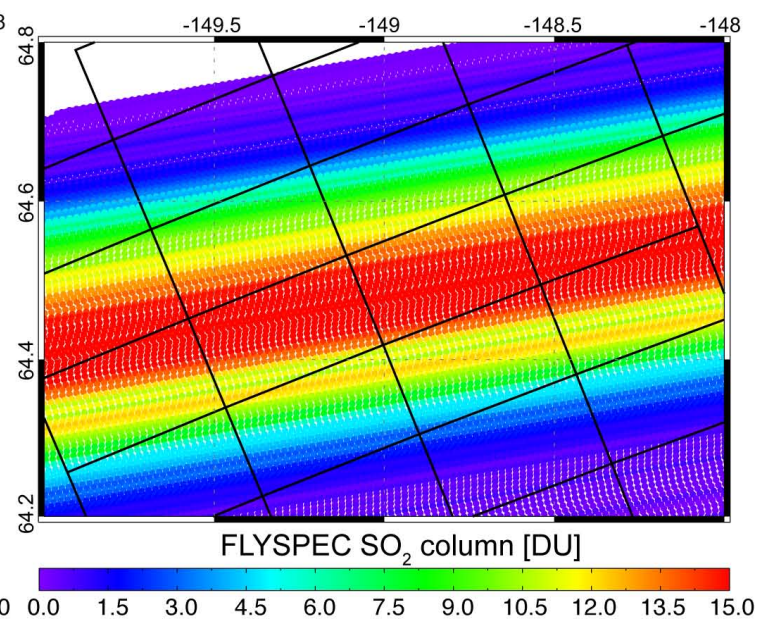

(d)

Fig. 3. (a) Aqua MODIS visible image of the region south of Fairbanks, AK on 18 June 2009 at 22:20 UTC with OMI pixel boundaries overlain in red (pixel dimensions are $\sim 13 \times 24 \mathrm{~km}$ ). OMI pixel numbers correspond to those in Table 1 . Note visible haze in the volcanic cloud across image center. (b) OMI SO 2 columns (22:28 UTC; colored pixels) and ground-based FLYSPEC $\mathrm{SO}_{2}$ traverse southbound from Fairbanks (periodically time stamped in UTC). OMI SO 2 color bar is shown in (c); FLYSPEC data color bar is shown in (d); (c) OMI $\mathrm{SO}_{2}$ columns (22:28 UTC) and ground-based FLYSPEC SO 2 traverse northbound towards Fairbanks; (d) lateral extrapolation of southbound traverse FLYSPEC data to assess effects of spatial averaging. OMI pixel boundaries are overlain in black.

a relatively smooth, symmetrical plume cross-section in the southbound traverse, are shown in Fig. 5. The FLYSPEC traverses intersected five near-nadir OMI pixels in orbit 26207 (Fig. 3), and the average FLYSPEC $\mathrm{SO}_{2}$ columns for each OMI pixel are reported in Table 1. We compute the OMI $\mathrm{SO}_{2}$ column for $\mathrm{SO}_{2}$ at $12-14 \mathrm{~km}$ altitude (we use $13 \mathrm{~km}$ ) by linear interpolation between the OMSO2 TRM and STL columns.

One factor that complicates the analysis is that the volcanic cloud was moving northwards during FLYSPEC data collection. Radiosonde soundings from Fairbanks (http://weather. uwyo.edu/upperair/sounding.html) at $12 \mathrm{Z}$ on 18 June and $00 \mathrm{Z}$ on 19 June indicate southerly to southeasterly winds at $\sim 2.6-5.1 \mathrm{~m} \mathrm{~s}^{-1}\left(9.4-18.5 \mathrm{~km} \mathrm{~h}^{-1}\right)$ at $13 \mathrm{~km}$ altitude, but with significant wind shear at $10-12 \mathrm{~km}$. This is consistent with the observation that $\mathrm{SO}_{2}$ was not detected over
Fairbanks at $\sim 21: 10$ UTC, but had drifted over Fairbanks by 00:15 UTC on 19 June and the northern flank of the plume was not detected in the northbound traverse (Figs. 3, 5). Radiosonde soundings from Anchorage, $\mathrm{AK}\left(61.22^{\circ} \mathrm{N}\right.$, $\left.149.90^{\circ} \mathrm{W}\right)$ and McGrath, AK $\left(62.96^{\circ} \mathrm{N}, 155.60^{\circ} \mathrm{W}\right)$ on $18-$ 19 June show similar wind patterns, although we note that the measurement location is situated in the lee of mountainous topography (the Alaska Range) and locally complex wind patterns could have affected the $\mathrm{SO}_{2}$ cloud. A consequence of the observed wind speed and direction relative to the size $(\sim 13 \times 24 \mathrm{~km})$ and orientation of the OMI pixels (Fig. 3) is that significant advection of $\mathrm{SO}_{2}$ would have occurred on timescales of $\sim 40-80 \mathrm{~min}$ (i.e., the time taken for winds at $\sim 10-20 \mathrm{~km} \mathrm{~h}^{-1}$ to travel $\left.13 \mathrm{~km}\right)$. For the spatially heterogeneous Sarychev $\mathrm{SO}_{2}$ cloud (Fig. 5), this complicates the interpretation of FLYSPEC measurements collected more 
Table 1. OMSO2 (orbit 26207; 22:28 UTC) and FLYSPEC data for Sarychev volcanic cloud pixels on 18 June 2009.

\begin{tabular}{|c|c|c|c|c|c|c|c|c|c|c|c|}
\hline \multirow[t]{2}{*}{$\begin{array}{l}\text { Pixel } \\
\text { No. }\end{array}$} & \multirow[t]{2}{*}{$\mathrm{xT}^{1}$} & \multirow[t]{2}{*}{$\begin{array}{l}\text { Lat } \\
\left({ }^{\circ} \mathrm{N}\right)^{2}\end{array}$} & \multirow[t]{2}{*}{$\begin{array}{l}\text { Lon } \\
\left({ }^{\circ} \mathrm{W}\right)^{2}\end{array}$} & \multicolumn{3}{|c|}{$\mathrm{OMI} \mathrm{SO}_{2}$ column (DU) } & \multicolumn{2}{|c|}{ Average FLYSPEC $\mathrm{SO}_{2}$ column (DU) } & \multirow[t]{2}{*}{$\begin{array}{l}\text { Cloud } \\
\text { fraction }^{8}\end{array}$} & \multirow[t]{2}{*}{$\mathrm{d}\left[\mathrm{SO}_{2}\right] / \mathrm{d} t\left(\mathrm{DU} \mathrm{h}^{-1}\right)^{9}$} & \multirow[t]{2}{*}{$\begin{array}{l}\text { Interpolated FLYSPEC } \\
\mathrm{SO}_{2}(\mathrm{DU})^{10}\end{array}$} \\
\hline & & & & $\mathrm{TRM}^{3}$ & $\mathrm{STL}^{4}$ & Interp..$^{5}$ & S. Traverse ${ }^{6}$ & N. Traverse ${ }^{7}$ & & & \\
\hline $\mathrm{P} 1$ & 29 & 64.70 & 148.47 & 3.6 & 3.4 & 3.5 & $1.0(2.4,2.1)$ & $14.2(14.0,12.3)$ & 0.57 & $5.7(5.0,4.4)$ & $9.2(9.7,8.4)$ \\
\hline $\mathrm{P} 2$ & 28 & 64.63 & 148.93 & 4.2 & 3.8 & 4.0 & $5.7(4.5,3.7)$ & $13.8(13.9,10.6)$ & 0.34 & $4.7(5.5,4.0)$ & $11.1(10.7,8.3)$ \\
\hline P3 & 28 & 64.51 & 148.83 & 7.8 & 6.9 & 7.3 & $14.5(14.7,12.6)$ & $13.9(12.5,10.5)$ & 0.25 & $-0.5(-1.7,-1.5)$ & $14.0(13.0,11.1)$ \\
\hline $\mathrm{P} 4$ & 27 & 64.44 & 149.29 & 7.6 & 6.7 & 7.1 & $15.3(14.5,12.4)$ & $10.0(9.8,8.3)$ & 0.25 & $-4.5(-4.2,-3.4)$ & $11.4(10.9,9.4)$ \\
\hline P5 & 27 & 64.32 & 149.18 & 3.3 & 3.0 & 3.1 & $6.3(6.0,5.0)$ & $2.0(1.9,1.6)$ & 0.27 & $-4.9(-4.7,-3.9)$ & $2.8(2.6,2.2)$ \\
\hline
\end{tabular}

${ }^{1}$ OMI cross-track pixel position (1-60;30 is nadir). ${ }^{2}$ Lat, Lon corresponds to center of OMI pixel. ${ }^{3}$ Collection 3 OMSO2 data for a SO 2 CMA of $7.5 \mathrm{~km}$ (TRM product). ${ }^{4}$ Collection $3 \mathrm{OMSO} 2$ data for a $\mathrm{SO}_{2}$ CMA of $17.5 \mathrm{~km}$ (STL product). ${ }^{5}$ TRM and STL OMSO2 columns linearly interpolated to a SO 2 cloud altitude of $13 \mathrm{~km}$. ${ }^{6}$ Average FLYSPEC $\mathrm{SO}_{2}$ column for southbound traverse from Fairbanks. Data in parentheses account for unweighted and weighted spatial averaging across the OMI pixel, respectively. ${ }^{7}$ Average FLYSPEC SO 2 column for northbound traverse towards Fairbanks. Data in parentheses account for unweighted and weighted spatial averaging across the OMI pixel, respectively. ${ }^{8}$ OMI-derived cloud fraction in pixel. ${ }^{9}$ Rate of change of $\mathrm{SO}_{2}$ column in each pixel based on southbound and northbound FLYSPEC surveys. Data in parentheses correspond to unweighted and weighted spatial averages within the OMI pixel, respectively. ${ }^{10}$ Estimated average FLYSPEC SO 2 column at time of OMI overpass (22:28 UTC). Data in parentheses correspond to unweighted and weighted spatial averages within the OMI pixel, respectively.

than $\sim 40-80$ min before or after the OMI overpass. This applies to pixel P1 in the southbound FLYSPEC survey, and all pixels with the exception of P5 in the northbound survey (Fig. 5).

Although MODIS data indicate possible meteorological cloud interference, OMI cloud fractions were quite low in most pixels (with the exception of pixel P1; Table 1) and OMI cloud pressures (not shown) imply predominantly lowaltitude clouds which would not significantly impact OMI retrievals of stratospheric $\mathrm{SO}_{2}$. The effect of clouds on the FLYSPEC measurements is unclear, but the general smoothness of the $\mathrm{SO}_{2}$ cross-sections (Fig. 5a) suggests no significant cloud interference in most pixels.

Comparison between the OMI $\mathrm{SO}_{2}$ columns and the average FLYSPEC $\mathrm{SO}_{2}$ columns for each OMI pixel reveals some significant differences (Table 1), but the relative timing of the measurements and spatial averaging of $\mathrm{SO}_{2}$ over the OMI pixels must be accounted for. In the absence of any ground-based constraints on horizontal variations in $\mathrm{SO}_{2}$ column, we assessed the effects of spatial averaging using a novel approach facilitated by A-Train satellite synergy. This technique involved extending the FLYSPEC $\mathrm{SO}_{2}$ columns laterally to simulate the 2-D distribution of $\mathrm{SO}_{2}$ in the volcanic cloud (Fig. 3d). The azimuth for this extrapolation is constrained using the location of maximum $\mathrm{SO}_{2}$ in the FLYSPEC profile $\left(64.27^{\circ} \mathrm{N}, 149.03^{\circ} \mathrm{W}\right.$; Fig. 5) and the location of the matching volcanic aerosol feature in CALIOP data $\left(64.49^{\circ} \mathrm{N}, 145.96^{\circ} \mathrm{W}\right.$; Fig. 2), giving an azimuth of $\sim 81^{\circ}$. This is qualitatively consistent with the $\mathrm{SO}_{2}$ distribution mapped by OMI (Fig. 3), but the technique clearly fails to account for any heterogeneity in the volcanic cloud. We then computed the mean of the simulated 2-D $\mathrm{SO}_{2}$ columns over the OMI pixels (Table 1), resulting in adjustments of only a few percent relative to FLYSPEC traverse averages for some pixels, but more substantial $(\sim 10-130 \%$; Table 1$)$ for others. Note that for some pixels (e.g., P1 in the southbound survey) the spatial average of the extrapolated FLYSPEC
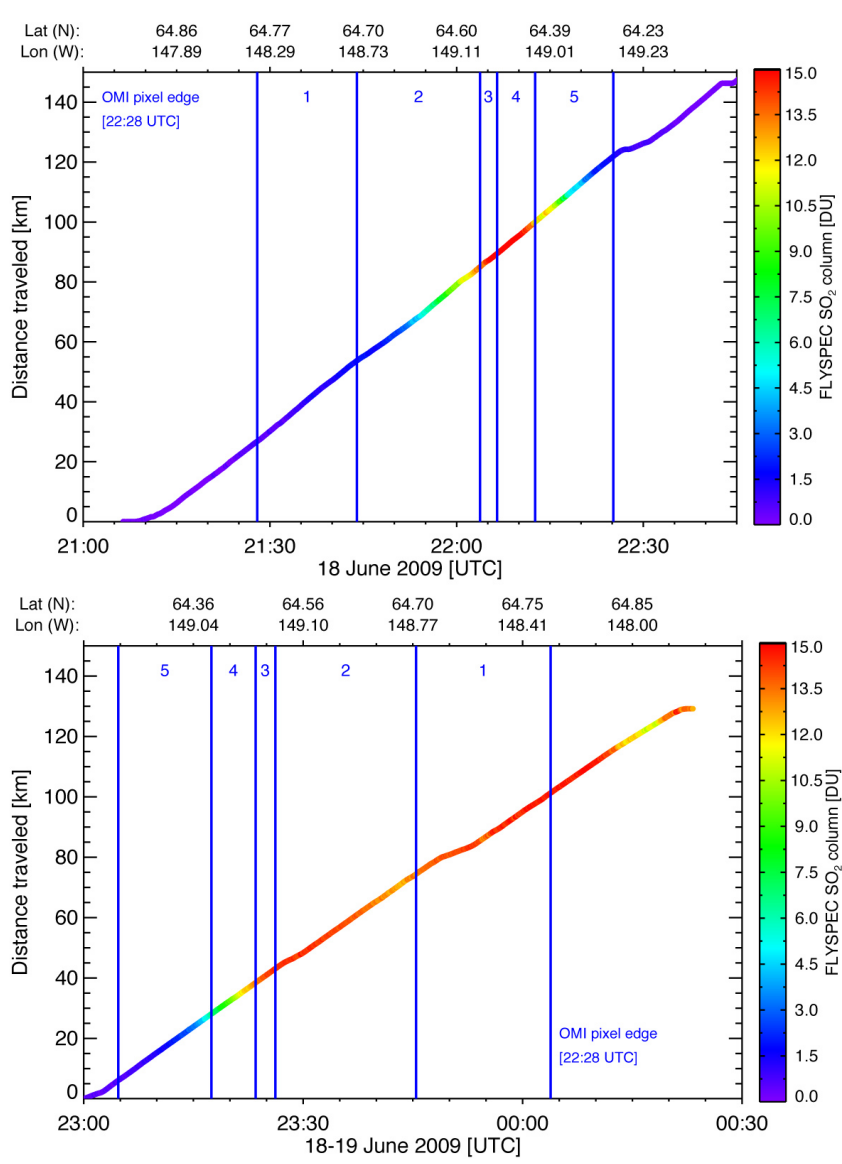

Fig. 4. Distance traveled during (top) southbound and (bottom) northbound FLYSPEC traverses of the volcanic cloud. The distance-time curves are color-coded by $\mathrm{SO}_{2}$ column amount, and OMI pixel boundaries are indicated. In each case the gradient of the curves yields an approximately constant speed of $\sim 100 \mathrm{~km} \mathrm{~h}^{-1}$ $\left(\sim 30 \mathrm{~m} \mathrm{~s}^{-1}\right)$. 

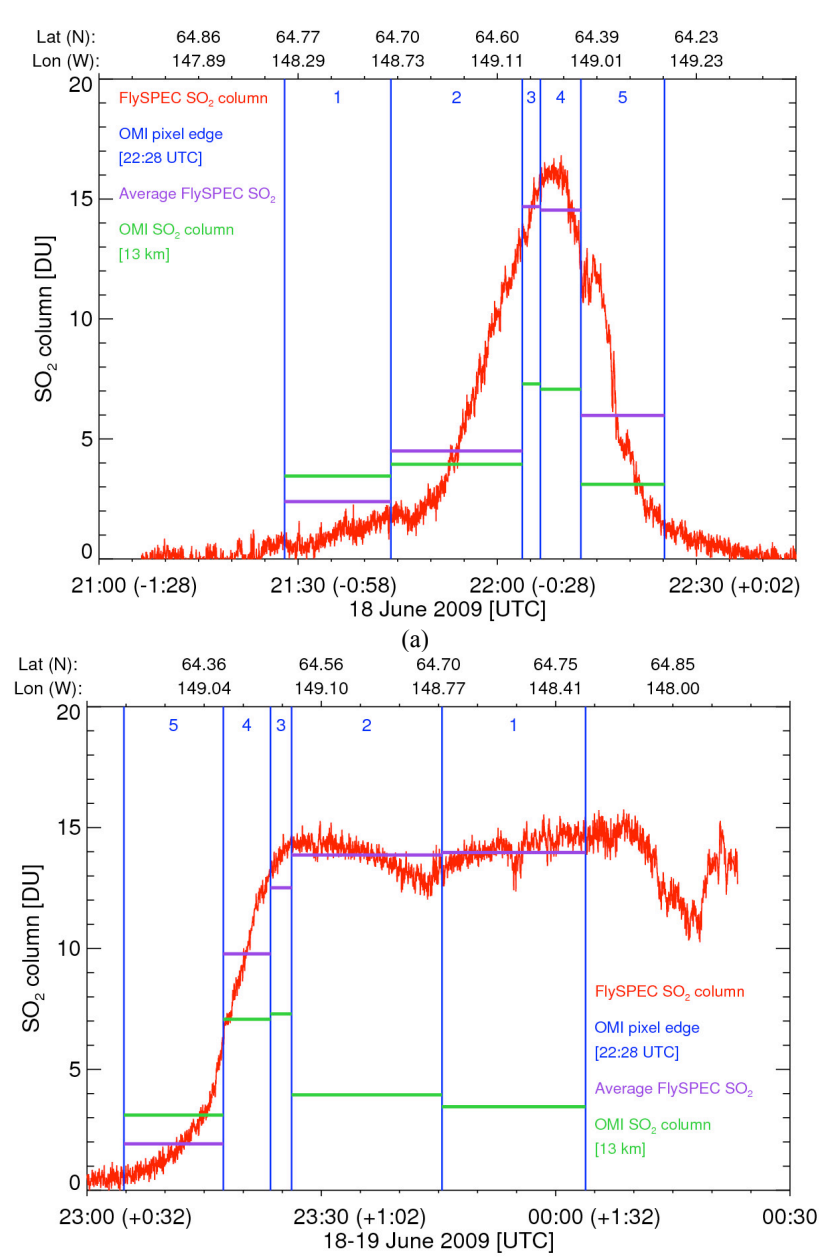

(b)

Fig. 5. FLYSPEC $\mathrm{SO}_{2}$ columns measured during traverses south of Fairbanks $\left(64.84^{\circ} \mathrm{N}, 147.72^{\circ} \mathrm{W}\right.$ ) along Route 3 (red line), OMI pixel boundaries for the 22:28 UTC Aura overpass (vertical blue lines; pixel numbers referred to in Table 1 are shown at top), extrapolated FLYSPEC $\mathrm{SO}_{2}$ columns averaged (unweighted) over corresponding OMI pixels (horizontal purple lines) and interpolated OMI $\mathrm{SO}_{2}$ columns in the same pixels (horizontal green lines). The abscissa shows FLYSPEC time; time relative to the Aura overpass is indicated in parentheses. (a) Southbound traverse from Fairbanks; (b) northbound traverse towards Fairbanks. The absence of a peak in (b) is due to northward drift of the volcanic cloud during measurement.

$\mathrm{SO}_{2}$ columns exceeds the mean of the raw FLYSPEC data for that pixel (Fig. 5a). In the case of pixel P1, this arises because the FLYSPEC traverse only characterized the northern half of the pixel, whereas the extrapolated $\mathrm{SO}_{2}$ amounts are higher in the southern half (Fig. 3d).

To account for temporal differences between the OMI and FLYSPEC measurements, we first calculate the temporal gradient in $\mathrm{SO}_{2}$ column amount for each pixel, based on the FLYSPEC measurements preceding and following the OMI overpass (Table 1). The resulting gradients are $\sim \pm 4$ $6 \mathrm{DU} \mathrm{h}^{-1}$ for all pixels except $\mathrm{P} 3$. We then interpolate the
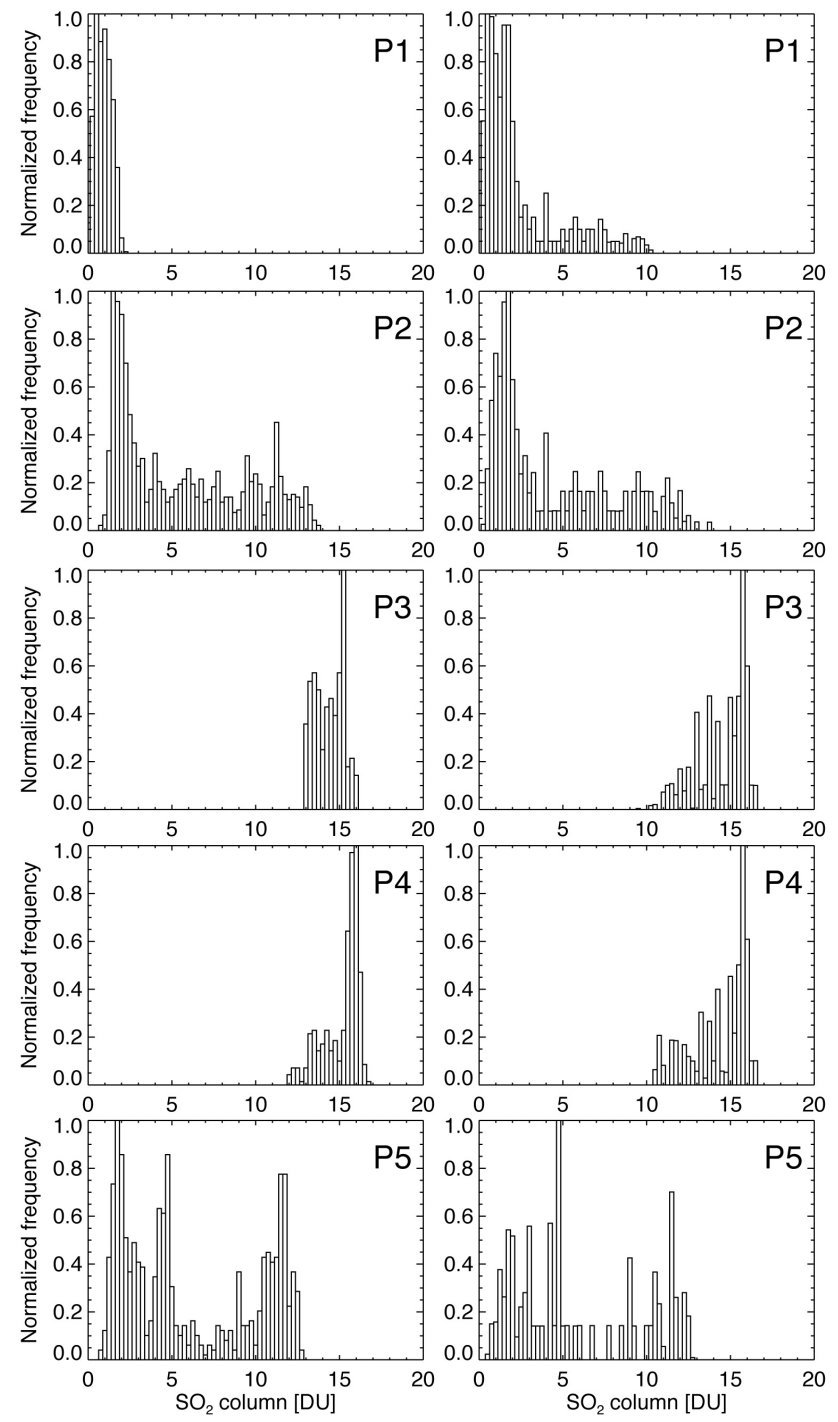

Fig. 6. Histograms of $\mathrm{SO}_{2}$ column amount for each OMI pixel surveyed by FLYSPEC during the southbound traverse from Fairbanks (Fig. 3). Each histogram pair shows the distribution for raw FLYSPEC measurements on the left, and unweighted spatially-averaged FLYSPEC data on the right. The ordinate shows the number of data points in each bin normalized to the mode.

$\mathrm{SO}_{2}$ column amounts for each pixel to the OMI overpass time (22:28 UTC) using these gradients (Table 1). These calculations also allow us to assess the relative magnitude of the spatial and temporal $\mathrm{SO}_{2}$ gradient for each pixel. In pixels $\mathrm{P} 2$, P4 and P5, which were surveyed in $\sim 20$ min or less (Fig. 5), the large spatial gradients in $\mathrm{SO}_{2}$ column (Figs. 4, 5) in either one or both of the FLYSPEC traverses indicate that adequate spatial characterization was required to validate these pixels. In pixels $\mathrm{P} 1$ and $\mathrm{P} 3$, the temporal gradient dominates, although as noted above P1 may have been impacted by a large meteorological cloud fraction (Table 1), and P3 is very poorly characterized in the spatial domain (Figs. 3, 4, 5). 
Two important results arise from this analysis. Firstly, we find the best agreement between the OMI and spatially averaged FLYSPEC measurements for pixel P2 (13\% difference; Table 1). We attribute this to the fact that pixel P2 has the best FLYSPEC data coverage of all the pixels, both along-track and across-track with respect to the OMI pixel geometry (Fig. 3), providing the best constraints on the subpixel $\mathrm{SO}_{2}$ distribution, despite a $\sim 30-45$ min time difference between the OMI and FLYSPEC measurements. This is corroborated further by inspection of histograms of $\mathrm{SO}_{2}$ column amount for each pixel (Fig. 6). These histograms show that the FLYSPEC traverse data for pixel P2 best match the mode and distribution of $\mathrm{SO}_{2}$ column amounts predicted for the entire pixel (Fig. 3d), which is a result of the good spatial characterization of this pixel.

Secondly, we also find good agreement between the OMI measurements (3.1 DU) and the interpolated FLYSPEC data for pixel P5 ( 11-19\% difference; Table 1). We attribute this to the fact that the FLYSPEC data were collected closest in time to the OMI overpass (Fig. 5). For the other pixels, the differences between the FLYSPEC and OMI measurements are significant and generally increase with temporal offset from the OMI overpass time (Table 1). This may indicate that the $\mathrm{SO}_{2}$ columns in each pixel were changing in a non-linear manner during the period of data acquisition, and hence the assumption of a linear $\mathrm{SO}_{2}$ column gradient, coupled with uncertainties on the spatial $\mathrm{SO}_{2}$ distribution, was inadequate for most pixels.

Differences between OMI and spatially averaged FLYSPEC $\mathrm{SO}_{2}$ columns are larger for the other analyzed pixels, particularly around the location of maximum $\mathrm{SO}_{2}$ (Table 1; Fig. 5a). This is perhaps best explained by spatial heterogeneity in the volcanic cloud that is not captured in our simple 2-D model of the plume (Fig. 3d). Furthermore, pixels P3 and P4 were not well-characterized by the FLYSPEC data and the traverses were close to the pixel boundaries, where the precise definition of the OMI spatial resolution becomes critical due to the variable OMI pixel spatial response function (SRF). All these factors may have contributed to the lower $\mathrm{SO}_{2}$ column measured by $\mathrm{OMI}$ in these pixels. It is likely that the larger cloud fraction in pixel P1 caused the relatively poor agreement for the southbound traverse (Fig. 3; Table 1). Increasing discrepancies are seen for the northbound FLYSPEC traverse data (Fig. 5b) as by this time the $\mathrm{SO}_{2}$ cloud had moved north over Fairbanks.

It is important to note here that the spatial resolution of OMI (or any CCD-array based spectrometer) cannot be simply represented by the mapped pixel edges (Figs. 3, 5). The SRF in both the flight- and across-track direction is approximately Gaussian in shape (Dobber et al., 2006). More precisely, the spatial resolution in the flight direction $(\sim 13 \mathrm{~km}$ at nadir) is defined as the full-width at half-maximum (FWHM) of the telescope instantaneous field-of-view (IFOV; $\sim 1^{\circ}$ ) convolved with a 2 -second integration time, while in the across-track direction it is the FWHM of the sum of the
Gaussian SRFs of 8 binned OMI CCD pixels $(\sim 24 \mathrm{~km}$ at nadir). Therefore, each OMI pixel is also influenced by photons received from beyond the mapped pixel boundaries. A detailed analysis of the OMI spatial resolution is beyond the scope of this paper, but we assessed the effect of non-uniform spatial response by weighting the FLYSPEC $\mathrm{SO}_{2}$ columns with a flat-topped Gaussian function (of the form $\mathrm{f}(x)=\exp (-$ $\left.c\left(x-x_{0}\right)^{4}\right)$, where $x-x_{0}$ is absolute distance from the pixel center $\left(x_{0}\right)$ in the along-track direction, and $c$ is a constant) to simulate an along-track SRF with FWHM corresponding to the mapped pixel boundaries. No attempt was made to account for contributions from beyond the FWHM pixel boundary, or to simulate the across-track SRF. The resulting weighted, spatially averaged FLYSPEC $\mathrm{SO}_{2}$ columns are $\sim 13-24 \%$ lower than the unweighted averages (Table 1 ) and improve some of the comparisons. For pixel P2, the OMIFLYSPEC difference for the southbound traverse reduces to $\sim 6 \%$, but for pixel P5, the OMI-FLYSPEC difference for the interpolated $\mathrm{SO}_{2}$ column increases to $\sim 30 \%$. Significant differences remain for the other pixels, which we conclude is probably due to unconstrained sub-pixel spatial heterogeneity in the volcanic $\mathrm{SO}_{2}$ cloud.

\section{Conclusions}

As this study demonstrates, validation of volcanic $\mathrm{SO}_{2}$ measurements is challenging, since acquisition of high-quality ground-based data may be precluded by time constraints. Nevertheless, we find good agreement between selected OMI and spatially averaged FLYSPEC $\mathrm{SO}_{2}$ data when some necessary assumptions about the 2-D $\mathrm{SO}_{2}$ distribution are invoked, providing additional support for the validity of the operational OMSO2 dataset (see also Spinei et al., 2010; Carn et al., 2011). Unresolved spatial heterogeneity in the volcanic cloud on a sub-OMI pixel scale coupled with non-linear temporal changes in $\mathrm{SO}_{2}$ column amount appear to be the best explanations for other observed OMI-FLYSPEC differences.

On the basis of this analysis, validation of satellite $\mathrm{SO}_{2}$ measurements in drifting volcanic clouds using sensors mounted on mobile platforms would only be recommended when the $\mathrm{SO}_{2}$ cloud is moving at a velocity much lower than that of the ground-based (or airborne) sensor. For clouds drifting at higher velocities, stationary ground-based measurements would provide better and more easily interpretable validation data (e.g., Spinei et al., 2010). The advantage of using mobile platforms is that multiple contiguous satellite sensor pixels can be surveyed. Furthermore, our analysis confirms that spatial coverage of pixel areas in both alongand across-track directions should be maximized to increase the likelihood of successful validation.

We conclude by stressing the uniqueness of our FLYSPEC $\mathrm{SO}_{2}$ dataset for the Sarychev Peak eruption, one of the last decade's largest explosive eruptions. As discussed above, the Sarychev volcanic cloud mostly resided at high 
Arctic latitudes, precluding widespread ground-based measurements. Perro et al. (2010) report ground-based Brewer spectrophotometer detection of $\mathrm{SO}_{2}$ from Sarychev over Eureka, northern Canada on 1 July 2009. To our knowledge, the FLYSPEC $\mathrm{SO}_{2}$ data presented here are the closest measurements to the eruption in time and location. The successful ground-based measurement of the volcanic $\mathrm{SO}_{2}$ cloud underlines the need for a widespread network of rapidly deployable instruments in order to successfully validate volcanic $\mathrm{SO}_{2}$ retrievals from satellite sensors.

\section{Supplementary material related to this article is available online at: http://www.atmos-meas-tech.net/4/1705/2011/ amt-4-1705-2011-supplement.zip.}

Acknowledgements. Funding for this work was provided by NASA (award no. NNX09AJ40G for Aura validation). We acknowledge the CALIPSO Science Team, Goddard Earth Science (GES) Data and Information Service Center (DISC), Langley Atmospheric Science Data Center (ASDC) and MODIS Rapid Response system for the provision of CALIPSO and MODIS data products in KMZ format. Two anonymous reviewers provided insightful comments that greatly improved the paper.

Edited by: K. Strong

\section{References}

Brinksma, E. J., Pinardi, G., Volten, H., Braak, R., Richter, A., Schönhardt, A., van Roozendael, M., Fayt, C., Hermans, C., Dirksen, R. J., Vlemmix, T., Berkhout, A. J. C., Swart, D. P. J., Oetjen, H., Wittrock, F., Wagner, T., Ibrahim, O. W., de Leeuw, G., Moerman, M., Curier, R. L., Celarier, E. A., Cede, A., Knap, W. H., Veefkind, J. P., Eskes, H. J., Allaart, M., Rothe, R., Piters, A. J. M., and Levelt, P. F.: The 2005 and 2006 DANDELIONS $\mathrm{NO}_{2}$ and aerosol intercomparison campaigns, J. Geophys. Res., 113, D16S46, doi:10.1029/2007JD008808, 2008.

Carn, S. A., Froyd, K., Anderson, B. E., Wennberg, P., Crounse, J., Spencer, K., Dibb, J., Krotkov, N. A., Browell, E. V., Hair, J. W., Diskin, G., Sachse, G., and Vay, S.: In situ measurements of tropospheric volcanic plumes in Ecuador and Colombia during $\mathrm{TC}^{4}$, J. Geophys. Res., 116, D00J24, doi:10.1029/2010JD014718, 2011.

Dobber, M. R., Dirksen, R., Levelt, P., van den Oord, G. H. J., Voors, R., Kleipool, Q., Jaross, G., Kowalewski, M., Hilsenrath, E., Leppelmeier, G., de Vries, J., Dierssen, W., and Rozemeijer, N.: Ozone Monitoring Instrument calibration, IEEE T. Geosci. Remote Sens., 44(5), 1209-1238, 2006.
Elias, T., Sutton, A. J., Oppenheimer, C., Horton, K. A., Garbeil, H., Tsanev, V., McGonigle, A. J. S., and Williams-Jones, G.: Comparison of COSPEC and two miniature ultraviolet spectrometer systems for $\mathrm{SO}_{2}$ measurements using scattered sunlight, B. Volcanol., 68, 313-322, 2006.

Gerlach, T. M.: Elevation effects in volcano applications of the COSPEC, in: Volcanic Degassing, edited by: Oppenheimer, C., Pyle, D. M., and Barclay, J., Geological Society, London, Special Publications, 213, 169-175, 2003.

Haywood J. M., Jones, A., Clarisse, L., Bourassa, A., Barnes, J., Telford, P., Bellouin, N., Boucher, O., Agnew, P., Clerbaux, C., Coheur, P., Degenstein, D., and Braesicke, P.: Observations of the eruption of the Sarychev volcano and simulations using the HadGEM2 climate model, J. Geophys. Res., 115, D21212, doi:10.1029/2010JD014447, 2010.

Horton, K. A., Williams-Jones, G., Garbeil, H., Elias, T., Sutton, A. J., Mouginis-Mark, P., Porter, J. N., and Clegg, S.: Real-time measurement of volcanic $\mathrm{SO}_{2}$ emissions: validation of a new $\mathrm{UV}$ correlation spectrometer (FLYSPEC), B. Volcanol., 68, 323-327, 2006.

Perro, C. W., Duck, T. J., Bitar, L., Nott, G. J., Lesins, G. B., O’Neill, N. T., Eloranta, E., Strong, K., Carn, S. A., Lindenmaier, R., Batchelor, R., Saha, A., Pike-Thackray, C., and Drummond, J. R.: Sarychev volcanic aerosol and chemical measurements over Eureka, Canada, Abstract A51B-0104 presented at 2010 Fall Meeting, AGU, San Francisco, CA, 13-17 December, 2010.

Spinei, E., Carn, S. A., Krotkov, N. A., Mount, G. H., Yang, K., and Krueger, A. J.: Validation of Ozone Monitoring Instrument $\mathrm{SO}_{2}$ measurements in the Okmok volcanic cloud over Pullman, WA in July 2008, J. Geophys. Res., 115, D00L08, doi:10.1029/2009JD013492, 2010.

Thomas, H. E. and Prata, A. J.: Sulphur dioxide as a volcanic ash proxy during the April-May 2010 eruption of Eyjafjallajökull Volcano, Iceland, Atmos. Chem. Phys., 11, 6871-6880, doi:10.5194/acp-11-6871-2011, 2011.

Vaughan, M., Young, S., Winker, D., Powell, K., Omar, A., Liu, Z., Hu, Y., and Hostetler, C.: Fully automated analysis of spacebased lidar data: an overview of the CALIPSO retrieval algorithms and data products, Proc. SPIE, 5575, 16-30, 2004.

Williams-Jones, G., Stix, J., and Nadeau, P. A.: Using the COSPEC in the Field, in: The COSPEC Cookbook: Making $\mathrm{SO}_{2}$, edited by: Williams-Jones, G., Stix, J., and Hickson, C., Measurements at Active Volcanoes, IAVCEI, Methods in Volcanology, 1, 63119, 2008.

Yang, K., Krotkov, N. A., Krueger, A. J., Carn, S. A., Bhartia, P. K., and Levelt, P. F.: Retrieval of large volcanic $\mathrm{SO}_{2}$ columns from the Aura Ozone Monitoring Instrument: comparison and limitations, J. Geophys. Res., 112, D24S43, doi:10.1029/2007JD008825, 2007. 